\title{
Desafios na Construção do Trabalho de Conclusão do Curso de Especialização em Negociação Coletiva / Modalidade a Distância
}

\author{
Elaine Di Diego Antunes, EA/UFRGS, eddantunes@ea.ufrgs.br \\ Nádia Brunetta, EA/UFRGS, nabrunetta@yahoo.com.br \\ Diogo Joel Demarco, EA/UFRGS, djdemarco@ea.ufrgs.br \\ Ivan Antônio Pinheiro, EA/UFRGS, iapinheiro@ea.ufrgs.br
}

\section{Resumo}

O presente trabalho objetiva apresentar os principais desafios enfrentados pelos alunos durante $\mathrm{o}$ processo de construção do trabalho de conclusão de um Curso de Especialização ofertado na modalidade a distância. $\mathrm{Na}$ discussão teórica são apresentadas noções conceituais acerca do processo de ensino-aprendizagem mediado por tecnologias e é feita uma reflexão, à luz da Pedagogia da Autonomia, sobre o perfil do aluno em EAD. Em termos metodológicos, adotou-se a estratégia de estudo de caso, sendo que as informações foram levantadas a partir de uma coleta via web com 288 dos 574 alunos matriculados no curso; suas respostas foram analisadas por meio da análise de conteúdo e de estatísticas simples. A justificativa deste estudo visa aperfeiçoar o processo de orientação do TCC servindo como subsídio para a equipe pedagógica, tutores e professores. Dentre os principais desafios destacam-se: escassez de tempo para conciliar atividades do curso com outros compromissos; dificuldade de compreensão e de uso das normas técnicas; problemas de relacionamento com tutores e orientadores; dificuldade para redigir textos científicos, obstáculos para acesso ao campo e aos materiais bibliográficos, entre outros. Para finalizar, são apresentadas recomendações possíveis de serem aplicadas em cursos EAD que exijam a elaboração e apresentação de um trabalho final.

Palavras Chave: Desafios; Trabalho de Conclusão de Curso; Ensino a Distância.

\section{Challenges when developing the conclusion's project in Negociação Coletiva Specialization Course / Distance Mode}

\begin{abstract}
This project's goal is to show the main challenges that the students go through during the production of the course conclusion's project in a specialization course offered in a distance mode. In the theoretic debate is presented conceptual ideas about the teaching process-learning mediated by technology and a reflection about the profile of the student who studies in a Distance Learning process is made, through the Pedagogy of Autonomy. In methodological terms, it was used the case study strategy and the information was raised through a collection via web with 288 of the 574 students enrolled in the course; their responses were analyzed through content analysis and simple statistics. The reason of this study aims at improving the Course Conclusion Project's guidance process serving as a contribution for the teaching staff, tutors and professors. Among the major challenges, stand out: lack of time to balance the course's activities with other appointments; difficulty in understanding and using of technical requirements; relationship issues with tutors and mentors; difficulty in writing scientific papers; obstacles to access the field and bibliographic materials, among other things. Finally, potential recommendations for application in distance education courses that require the preparation and presentation of the final project are presented.
\end{abstract}

Keywords: Challenges, Course Conclusion Project, Distance Learning. 


\section{Introdução}

O Curso de Especialização em Negociação Coletiva - modalidade a distância foi planejado com o propósito de ampliar as competências dos servidores públicos federais. A proposta do curso objetiva a formação de profissionais capazes de articular, mobilizar e colocar em ação valores, conhecimentos e habilidades necessárias para o desempenho das atividades requeridas pela natureza do trabalho. Destaca-se como objetivo principal do curso a contribuição no processo de institucionalização da negociação coletiva na Administração Pública Brasileira, fomentando uma mudança de cultura no âmbito das relações de trabalho nas organizações públicas brasileiras, criando uma massa crítica de servidores públicos federais - da administração direta, autárquica e fundacional - capazes de atuar nos processos de negociação coletiva no setor público. Com esse intuito surgiu a parceria entre a UFRGS e a Secretaria de Recursos Humanos do Ministério do Planejamento, Orçamento e Gestão (MPOG). O curso foi organizado com a intenção de promover momentos de interação entre seus participantes e promover a aplicabilidade dos conteúdos teóricos desenvolvidos nas disciplinas, no contexto profissional dos servidores públicos, culminando num projeto final que serviria como base para elaboração do trabalho de conclusão de curso - requisito obrigatório para a obtenção da certificação pretendida, desde que atendidos os critérios de avaliação estipulados pela coordenação pedagógica e estabelecidos no projeto pedagógico.

Nesta oferta, 574 discentes foram matriculados no curso de Negociação Coletiva e alocados em sete pólos do país: Belém (PA); Belo Horizonte (MG); Brasilia (DF); Porto Alegre (RS); Recife (PE); Rio de Janeiro (RJ) e São Paulo (SP). Os alunos contaram com os recursos do ambiente virtual de aprendizagem NAVi durante a oferta das disciplinas, especialmente no processo de orientação do Trabalho de Conclusão do Curso (TCC) e na preparação para as bancas - quando então dispuseram de vários recursos: chats, fóruns temáticos, biblioteca virtual, vídeos, teleconferências, entre outros.

Após a oferta da disciplina de Metodologia Científica, optou-se por realizar os Seminários temáticos de Monografia com as turmas reorganizadas, não mais pelo critério de localização geográfica e sim de acordo com o tema escolhido para o desenvolvimento do TCC. A orientação foi estruturada da seguinte forma: (1) orientação individual dos alunos utilizando diversos canais: (áudio) chats pelo ambiente virtual de aprendizagem, e-mail, Skype, MSN, Google Talk, postagem no Portfólio, etc., conforme agendamento feito com o tutor; (2) foi obrigatório o agendamento de, no mínimo, 4 (quatro) "encontros" de orientação individual mediados com os alunos.

Foram abertos, no ambiente virtual de aprendizagem, dois fóruns obrigatórios, um deles denominado "Fórum de Orientação do TCC" (aberto no início das orientações e ficou disponível durante quase cinco meses destinados ao período de orientação). $\mathrm{O}$ outro fórum foi o de Registro das Orientações - neste o tutor teve de registrar até mesmo quando um aluno faltava a uma sessão de orientação, mediada por ele e orientada pelo professor. O professor orientador acompanhou o atendimento e as dificuldades dos alunos através dos tutores. Alguns casos extremos de dificuldades entre alunos e tutores foram tratados de forma personalizada pela coordenação do curso.

Diante do cenário problematizado, a questão norteadora deste artigo é: quais são os principais desafios enfrentados pelos alunos durante o processo de elaboração do trabalho de conclusão do Curso de Negociação Coletiva? Esta reflexão permitirá uma avaliação das principais dificuldades apontadas pelos alunos e poderá oportunizar um olhar para novas possibilidades de ação, visando à proposição de diretrizes que 
possibilitem a melhoria do processo de orientação do trabalho de conclusão dos cursos realizados a distância, os quais requerem orientações de grande quantidade de alunos, poder-se-ia dizer, um processo de ensino-aprendizagem em massa, mas com atendimento personalizado, direto, individual e próximo.

\section{O processo de ensino-aprendizagem mediado por tecnologias}

$\mathrm{Na}$ educação mediada por tecnologias, para desenvolver uma prática colaborativa e cooperativa é preciso ter a sensibilidade de ouvir e respeitar o outro, assim é possível perceber que "quem ensina aprende ao ensinar e quem aprende ensina ao aprender" (Freire, 2000, p. 23). Nesse sentido, Silva (2006) reconhece a interatividade como "o espírito de um novo tempo, uma revolução na comunicação", aproximando-se, assim, tanto interação quanto interatividade do universo da comunicação, muito mais que da informática (Litto, 2009).

Abordando o ensino a distância como palco do ensino e da interatividade, considera-se que sua maior contribuição está na possibilidade de separação física entre professor e aluno, sem que, com isso, se perca o caráter de interação - síncrona ou assíncrona - mantendo-se a relação triádica característica do processo de ensino. A EAD utiliza-se de meios técnicos para garantir essa interação, flexibilizando o aprendizado em termos temporais e locais. Inegável, no entanto, as relações interativas (Litto, 2009) que se estabelecem nessa opção de ensino entre: (1) Aluno/professor: este processo de interação ocorre quando o circuito de mensagens flui entre os personagens. Assim, a interação somente aconteceria se o professor, ao responder um questionamento do aluno, recebesse seu feedback e fizesse um novo comentário, como num debate em que houvesse a "réplica" e a "tréplica"; (2) Aluno/conteúdo: os alunos podem interagir com diferentes conteúdos e objetos de aprendizagem, tais como: som, texto, imagens, vídeos, etc., através da navegação, exploração, seleção e controle; (3) Aluno/aluno: pode ocorrer síncrona e assincronamente, caracterizando o aprendizado colaborativo e cooperativo. Essa interação desenvolve o senso crítico e a capacidade de trabalhar em equipe, podendo criar a sensação de pertencer a uma comunidade.

A importância destes momentos de interação entre os participantes do curso é descrita por Maçada e Tijiboy (1998. p.3) como:

\footnotetext{
(...) a interação ("inter-ação") é o elemento básico e inicial de todo o processo, pois é ela que abre o canal de comunicação. Mas ela também está e deve estar presente ao longo de todo o trabalho em grupo possibilitando uma negociação constante entre os sujeitos envolvidos. Viabilizando o aprendizado através das relações interpes soais.
}

Outros tipos de interação possíveis são mencionados por autores (Nevado, 2005; Belloni, 2003; Almeida, 2003), alguns propõem classificação em função dos agentes envolvidos, outros observam a influência mútua entre o aluno e seu entorno e há ainda os que defendem uma interatividade social, que incluiria aspectos da comunicação como linguagem corporal, troca de informações pessoais e motivação do aluno, num contexto que iria para além da sala de aula. Independente do tipo é importante considerar que o grau das interações varia em função das mídias utilizadas e a combinação planejada dessas diferentes formas de interação é um dos desafios da EAD. 


\section{Pedagogia da Autonomia: reflexão sobre o perfil do aluno em EAD}

O indivíduo é um ser de relações "ele está no mundo e com o mundo" (FREIRE, 1979, p. 30) e esta capacidade de relacionamento interpessoal pode ser reflexiva, quando se consegue fazer com que o educando reflita sobre sua própria realidade; pode ser consequente, quando resultam da criação e recriação, fazendo o indivíduo ser capaz de transformar a realidade; e pode ser transcendente e temporal porque é possível estabelecer relação com infinitos seres (FREIRE, 1979).

"Ensinar não é transferir conhecimento, mas criar as possibilidades para a sua produção ou construção" (FREIRE, 1996, p. 22). Deve haver uma troca: quem ensina, aprende ao ensinar e quem aprende, ensina ao aprender e para que isso seja possível, é necessário conhecer e valorizar as experiências relatadas. $\mathrm{Na}$ verdadeira aprendizagem os educandos são sujeitos da construção do conhecimento, assim como o educador também é sujeito desse processo. Professores e alunos devem ter consciência que suas atitudes precisam ser dialógicas, abertas, indagadoras, não apassivadas e que tais características não invalidam os momentos explicativos e narrativos, em que o professor expõe um conteúdo (FREIRE, 1996).

É importante que o indivíduo assuma eticamente a responsabilidade de suas ações e decisões, porque isto interfere no processo de construção da autonomia, que se constitui nas repetidas experiências de decidir "ninguém educa ninguém" (FREIRE, 1979, p. 28) e "ninguém é sujeito da autonomia de ninguém" (FREIRE, 1996, p. 107), o amadurecimento acontece de forma gradativa, portanto, a pedagogia da autonomia deve ser pautada em experiências que estimulem as decisões e o senso de responsabilidade, as chamadas "experiências respeitosas da liberdade" (FREIRE, 1996, p. 107).

A EAD também é estimuladora da autonomia do aluno, sobretudo porque a distância física entre os atores do processo de ensino e aprendizagem possibilita aos alunos o desenvolvimento da habilidade de gerenciamento do tempo e aprendizado, já que precisam estabelecer e planejar períodos de estudo e organizar a prioridade dos conteúdos a serem estudados (PASSARELI, 2007).

$\mathrm{O}$ processo de aprendizagem intermediado por recursos tecnológicos, como a utilização de um AVA, possibilita uma concepção interacionista à medida que proporciona um espaço de interação entre os atores envolvidos (alunos, professores e tutores) para troca de experiências e construção colaborativa do conhecimento.

Num espaço em que ocorrem interações entre o sujeito e o objeto de estudo, a construção do conhecimento se consolida através da ação do sujeito (aluno), que a partir das informações emitidas (via chat, fórum, mensagens e outros recursos) pelo tutor ou professor, deve buscar explorar e se apropriar do conhecimento transmitido. Neste sentido, uma relação dinâmica é estabelecida entre os agentes, onde o professor é o mediador, o instigador, o problematizador e o aluno torna-se o protagonista no processo de ensino (SCHLEMMER, 2005).

Moore (2003) defende que a principal característica da Educação a Distância está justamente em possibilitar a autonomia e a independência da aprendizagem no aluno adulto e destaca que é para este público que a EAD está prioritariamente dirigida. Sendo a educação um processo individual, os alunos estariam capacitados para exercer sua decisão sobre o que aprender e em que ritmo fazê-lo.

\section{Procedimentos Metodológicos}


O presente estudo adota uma perspectiva exploratória, por tratar de algo pouco estudado, ou seja, o objeto analisado refere-se ao processo de construção do trabalho de conclusão de um curso de especialização ofertado na modalidade a distância, no campo da administração pública federal, sob a perspectiva pedagógica. A pesquisa caracterizase pela estratégia de estudo de caso, por estudar um fenômeno contemporâneo num determinado contexto (Yin, 2001) e foi elaborada com base em dados primários extraídos de informações coletadas através de questionários aplicados via web aos alunos matriculados no curso.

Todos os alunos matriculados no curso (574) foram convidados a participar da pesquisa. O retorno da avaliação do curso efetuada no período do dia 01.02.11 a 04.02.2011 foi bastante significativo.: obteve-se 50\% de retorno, o que representa uma margem de erro de 4.08, com intervalo de confiança de $95 \%$. A amostra é representativa de todos os pólos e órgãos ou entidades nas quais os alunos do curso estão alocados.

Os participantes deste estudo responderam a um questionário avaliando a proposta do curso e as atividades desenvolvidas durante os semestres letivos, com ênfase à fase de elaboração do trabalho de conclusão de curso. Dos 288 respondentes, a maioria se caracteriza por: pertencer ao sexo feminino (61\%); possuir mais de 40 anos de idade (66\%); pretender aposentar-se ainda nesta década, ou seja, entre o período de 2011 a 2020 (perfazendo 46\% da amostra); não mudou de órgão ou entidade durante o curso (86\%); não havia cursado e concluído algum curso de pós-graduação Lato Sensu (61\%); não havia cursado e concluído algum curso de pós-graduação Stricto Sensu (91\%); ter cursado Administração, Direito e Ciências - Sociais, Contábeis, Econômicas - $(55 \%)$.

Como técnicas de análise, fez-se uso da análise documental e da análise de conteúdo, para as questões abertas e de estatísticas simples (percentuais e médias) para interpretar as respostas dos alunos. Outras técnicas de coleta usadas, visando à triangulação das informações, foram: pesquisa em dados secundários em relatórios gerenciais e informações acadêmicas do curso.

\section{Contextualizando a avaliação dos alunos: aspectos preliminares}

Os alunos deveriam atender alguns critérios estabelecidos no projeto pedagógico do curso para obterem a certificação correspondente, ou seja, deveriam obter aprovação em todas as disciplinas e aprovação no trabalho de conclusão. $\mathrm{O}$ trabalho final visava a integração dos temas estudados, corroborando com o fortalecimento do perfil do egresso que o curso objetivava formar, através do desenvolvimento das competências estabelecidas.

Para a formação do profissional, o curso ofereceu 405 horas/aula, distribuídas nas seguintes disciplinas: (1) Aprendendo a aprender a distância; (2) Estado, Governo e Sociedade; (3) Ética, Cultura e Valores; (4) Relações e Organizações de trabalho; (5) Negociação I, (6) Negociação II; (7) Negociação III; (8) Multiplicação e desenvolvimento de competências em programas de formação e treinamento; (9) Metodologia Científica; (10) Seminário temático de monografia de especialização.

Ao término das disciplinas, sob a supervisão de um Professor-Orientador vinculado ao curso e com a mediação do tutor, cada aluno produziu individualmente, um trabalho de conclusão no formato de artigo ou de monografia. Em se tratando de um curso patrocinado pelo Ministério do Planejamento, Orçamento e Gestão (MPOG), o tema do trabalho final foi relacionado aos assuntos considerados estratégicos pelo MPOG. 
O trabalho final foi apresentado e avaliado, presencialmente, por dois professores vinculados ao curso. Excepcionalmente, mediante justificativa documentada, foi admitida a apresentação na modalidade de videoconferência, neste caso, o professor pôde participar remotamente, mas em tempo real, da banca avaliadora, seguindo os mesmos critérios de avaliação de uma apresentação realizada presencialmente. Os critérios de avaliação foram divulgados previamente através de um instrumento de avaliação, sendo que antes das bancas ocorrerem foram solicitadas a auto avaliação do aluno e a avaliação do tutor-orientador sobre o trabalho desenvolvido e que seria avaliado pelos professores membros das bancas. Essas avaliações, se comparadas com as avaliações obtidas pelos professores das bancas, mostram-se bastante paradoxais, como será demonstrado adiante.

Enfim, através de uma pesquisa com os alunos procurou-se identificar os principais desafios enfrentados por estes durante a fase de construção do trabalho de conclusão de curso, pois ficou evidente que os alunos apresentaram grande dificuldade na etapa final do curso, especialmente no que concerne à elaboração do TCC, ocasionando, por vezes, a reprovação no projeto ou na monografia daqueles que haviam tido desempenho satisfatório nas demais disciplinas regulares componentes da matriz curricular.

Dos 574 alunos iniciais, 410 chegaram ao processo de elaboração do TCC, estando aptos para iniciarem o processo de orientação. Destes, 354 encaminharam seus trabalhos para defesa, sendo que 24 não compareceram à banca por terem sido previamente avisados pelo tutor e professor orientador acerca de fragilidades do trabalho e consequente risco de reprovação. Ao final, 266 alunos obtiveram aprovação, demonstrando que o índice de aprovação daqueles que receberam orientação foi favorável, correspondendo a $65,12 \%$ do total.

\subsection{Os Desafios para a construção do Trabalho de Conclusão de Curso, sob a perspectiva dos alunos}

Diversos aspectos foram mencionados pelos alunos, destacam-se os seguintes desafios: administrar o tempo, ter acesso ao campo a ser pesquisado e aos materiais bibliográficos, redigir um texto científico, relacionamento com tutor, falta de motivação pessoal para elaborar o projeto, falta de orientação presencial (do professor e/ou tutor) e dificuldade para utilizar computadores e outros recursos tecnológicos.

Quanto à dificuldade para administrar o tempo, constata-se que muitos dos alunos alegaram ter uma sobrecarga de trabalho; em especial, na fase de conclusão do curso (final do ano de 2010), argumentando ser bastante difícil conciliar atividades profissionais e pessoais (casa, filhos, outros compromissos) e ainda conseguir atender os prazos de entrega das etapas parciais do projeto de trabalho de conclusão de curso. Outros problemas de cunho pessoal, tais como: doenças, mudança de residência, gravidez, divórcio, entre outros, também receberam destaque e teriam sido as principais justificativas utilizadas para solicitação de prorrogações dos prazos de entrega. Sobre a administração do tempo cabe comentar que, atendendo aos pedidos dos alunos, houve prorrogação do período de orientação para mais dois meses, aumentando assim a oportunidade de desenvolver um trabalho adequado às exigências propostas pelo curso e apresentadas não somente durante a disciplina de Metodologia, mas também nas interações entre tutores, alunos e professores, especialmente porque no período destinado a orientação de TCC, havia orientações individuais e personalizadas, que eram realizadas através de chats em tempo real e outros recursos já mencionados, que 
possibilitaram o esclarecimento das dúvidas, para desenvolvimento das etapas subsequentes do trabalho final. Como apresenta Freire, a autonomia é essencial neste processo, que exige tempo e dedicação do aluno, além de exigir também rigorosa disciplina para que seja capaz de organizar seus estudos e conciliar as atividades acadêmicas com outros compromissos.

Alguns alunos mencionaram que não tiveram acesso ao campo a ser pesquisado para coleta de informações e dados ou tiveram demora na obtenção das respostas solicitadas e, consequentemente, isto acarretou atraso na compilação e análise dos dados. Esta situação também teria corroborado para o desencadeamento de dificuldades na etapa de tabulação e análise dos dados coletados para a pesquisa.

Houve menção sobre a dificuldade para acesso a materiais bibliográficos para realização de pesquisas, com destaque ao argumento de que os alunos (em sua maioria) residiriam longe de grandes bibliotecas e não teriam facilidade para acesso a materiais atualizados. Entraria aqui a questão da territorialidade, que poderia ser sanada através da busca de materiais digitalizados em periódicos de acesso on-line. Contrariamente, constata-se que os alunos que tiveram acesso a materiais de pesquisa, reclamaram sobre a "elevada" carga de leitura e pesquisa que o TCC exige de "uma só vez". Cabe destacar que a Biblioteca Virtual da Escola de Administração da UFRGS organizou e ofereceu um acervo completo de materiais relacionados aos temas de pesquisa, incluindo anais de eventos; leis, decretos e atos normativos; livros; periódicos; revistas científicas; teses e dissertações, entre outros.

Durante a elaboração do trabalho de conclusão, alguns aspectos técnicos e operacionais também foram citados, além de aspectos ligados à formação básica dos autores e as suas práticas de leitura e escrita. Verificam-se desde dificuldades para "colocar as ideias no papel" até a limitação para redigir textos de acordo com o modelo de redação científica, além dos obstáculos para compreender e aplicar as normas técnicas da $\mathrm{ABNT}$, principalmente devido à falta de conhecimento sobre técnicas de pesquisa e metodologia, segundo os respondentes. Contudo, essa opinião não se justifica ao se analisar o material disponibilizado (slides, textos, vídeos, manuais, exemplos de trabalhos, guia de normas técnicas etc.). Os alunos mencionaram que foi difícil delimitar o tema de pesquisa e definir seus objetivos de estudo e que isto poderia estar ligado à inexperiência ou seria consequência de um período de afastamento dos estudos (aspecto mencionado por aqueles que terminaram a graduação e ficaram alguns anos longe do meio acadêmico). Cabe lembrar que 66\% da amostra é formada por alunos com mais de 40 anos de idade e que $46 \%$ deles pretende se aposentar ainda nesta década.

Observa-se ainda que muitos alunos atribuíram o desempenho insatisfatório a problemas de relacionamento com os orientadores do TCC (professores e tutores) e neste aspecto foram mencionados: demora para recebimento de feedback; pouca afinidade com o orientador, falta de esclarecimentos diretos e pontuais sobre o que precisava de fato ser melhorado durante a construção do trabalho, ausência ou demora para orientação, entre outros. Alguns alunos foram diversas vezes alertados sobre o risco de cometerem plágio, outros - por reiterarem na apropriação indevida das palavras e ideias de outros autores - foram advertidos que tal ocorrência se configura como falta grave no estatuto da Universidade, podendo ocasionar a reprovação.

Os discentes que concluíram efetivamente o TCC e foram encaminhados para apresentarem seus trabalhos em banca mencionaram que tiveram sentimentos relacionados à ansiedade e medo dos avaliadores e que estas emoções também teriam influenciado sua apresentação, o que prejudicou a avaliação. Aspectos relacionados à 
falta de motivação para elaborar o projeto, falta de orientação presencial (do professor ou tutor), dificuldade para utilizar computadores e outros recursos tecnológicos (por exemplo, acessar a biblioteca virtual e os vídeos, dependendo da região do país e da capacidade tecnológica local), também foram mencionados pelos alunos.

Entretanto, grande parte dos alunos apontou a percepção da necessidade deles próprios estudarem e se dedicarem mais na etapa de construção do trabalho de conclusão de curso e, neste ponto, fica evidente a importância de construírem a concepção do que se pretende pesquisar no trabalho de conclusão em fases anteriores à etapa final do curso. Isto sugere que a disciplina de Metodologia e a elaboração do projeto e do trabalho nas próximas edições do curso podem vir a ser transversais, ou seja, podem acontecer simultaneamente com as disciplinas regulares.

Um resultado que chama a atenção diz respeito à falta de compreensão dos critérios de forma e conteúdo exigidos num trabalho de conclusão, mesmo depois de haver ampla divulgação das informações necessárias, inclusive em relação às normas técnicas. Talvez isto tenha influenciado na realização de plágios, pois foram constatadas reproduções literais de trabalhos acadêmicos já apresentados e de trechos de publicações, o que acarretou a reprovação de alguns alunos. Quanto aos reprovados, diversos são os argumentos apresentados pelos alunos na tentativa de justificar um desempenho considerado insatisfatório na fase crucial do curso e o conhecimento destes relatos é importante para que possam ser estabelecidas novas ferramentas de apoio e monitoramento durante o processo de orientação do trabalho de conclusão de curso, em busca da otimização desta etapa final e crítica.

Vale ressaltar que, se por um lado, os alunos mencionaram dificuldade de contatarem seus tutores e professores orientadores (pela distância física e que esta condição teria interferido na elaboração do TCC), por outro lado, eles admitem ser necessários maior dedicação e empenho durante a fase final do curso, compreendendo a importância de ampliar a quantidade de leitura, pesquisa e tempo dedicado a elaboração da monografia. Cabe lembrar que, durante o processo de orientação, houve acompanhamento no número de contatos realizados entre alunos, seus tutores $\mathrm{e}$ professores, sendo que alguns discentes não cumpriram os requisitos mínimos de interação. Enfim, destaca-se mais um paradoxo no processo de construção e orientação do TCC.

A maioria dos casos de reprovação foi devida à prática de plágio, este entendido como cópia, total ou parcial de texto significativo ao contexto, sem a devida citação do autor e a respectiva referência bibliográfica. Cumpre esclarecer que o plágio não raro se faz acompanhar de outras limitações, consideradas graves aos textos acadêmicos: a insuficiência de redação própria, fragmentação e descontinuidade do texto e, por conseguinte a ausência de organicidade da obra; os alunos que justificadamente faltaram à banca tiveram uma nova e última oportunidade; aos alunos que tiveram os seus trabalhos com avaliação condicionados foi ofertada a continuidade de orientação, contudo, repetiu-se o comportamento anteriormente verificado: nem todos buscaram, tempestivamente, o apoio disponibilizado. Neste caso, a aprovação final dependia da declaração do tutor-professor responsável de que as solicitações haviam sido atendidas e da verificação por parte da banca solicitante; do total de alunos, 23 alunos optaram por não fazer as alterações propostas, sendo, pois, considerados desistentes e reprovados.

\section{Considerações Finais}


Neste artigo foi apresentada uma problemática usual nos cursos realizados a distância que exigem a elaboração e apresentação de um trabalho de conclusão de curso. Problemática essa usual numa modalidade de ensino que vem se expandindo significativamente nas instituições de ensino brasileiras, mas que ainda não está sendo devidamente explorada nos estudos acadêmicos. Então, observando-se essa lacuna, teórica e empiricamente, é que se buscou investigar exploratoriamente o ponto de vista discente sobre os desafios enfrentados durante o processo de realização do trabalho de final de curso, com base na experiência recente dos alunos do Curso de Especialização em Negociação Coletiva. Certos achados da pesquisa mostraram-se contraditórios e ambíguos, principalmente se analisados à luz dos documentos disponibilizados a todos partícipes do curso (alunos, professores, tutores, coordenadores e equipe de apoio).

Em síntese, o principal desafio apresentado pelos alunos no que concerne ao processo de construção do trabalho de conclusão está relacionado à escassez de tempo. De acordo com as informações levantadas na pesquisa, pode-se inferir como sendo esta uma dificuldade para administrar o tempo, efetivamente, com autonomia e com auto responsabilização por parte do aluno, tal como sugere Freire (1996; 2000). Cabe ainda recuperar o que declara Passareli (2007), quando entende a educação a distância como estimuladora da autonomia do aluno, haja vista que a distância física entre os envolvidos requer do aluno o gerenciamento do tempo e do seu aprendizado.

A dificuldade em termos de falta de tempo foi reconhecida por grande parte dos respondentes. Apesar disto, reconhecem, pois, a necessidade de estudarem e se dedicarem mais na etapa de construção do trabalho de conclusão de curso e, neste ponto, sugerem a importância de construírem a concepção do que se pretende pesquisar no trabalho de conclusão, em fases anteriores à etapa final do curso. Isto sugere que seria oportuno que a disciplina de Metodologia Científica e a elaboração do projeto e do trabalho, nas próximas edições do curso ou em outros cursos desta modalidade, sejam oferecidas de modo transversal, ou seja, poderiam acontecer simultaneamente às disciplinas regulares do curso.

Para finalizar e visando atender a justificativa exposta pela realização deste estudo preliminar em um campo científico em que as pesquisas ainda são incipientes, são apresentadas algumas diretrizes a título de recomendações às instituições de ensino que fazem uso do ensino a distância e tem como um dos requisitos para o oferecimento da titulação a aprovação do aluno no trabalho de conclusão. São sugeridas as seguintes recomendações:

(1) alterações no desenho da disciplina de Metodologia Científica e na data de início do processo de orientação, passando essa a ocorrer desde o início do curso até sua finalização;

(2) comunicação clara, direta e constante acerca dos critérios de avaliação, bem como o uso de um instrumento único e validado de avaliação do trabalho final;

(3) avaliação continuada e de múltiplas fontes, durante as orientações e a fase de preparação para as bancas. O sistema avaliativo poderia ser baseado no modelo de avaliação 360 ou 180 graus, ou seja, com a participação de tutores, auto avaliação e, dependendo das dissonâncias, com a intervenção avaliativa do professor para antecipar os resultados da banca; assim, o aluno iria mais seguro para arguir diante dos professores ou evitaria constrangimentos, tendo conhecimento prévio das qualidades e das limitações de seu trabalho, para, posteriormente, obter a avaliação final dos membros da banca; 
(4) apresentação de um guia de normas técnicas (de acordo com a ABNT) e de exemplos de trabalhos de alunos que souberam aplicá-las adequadamente;

(5) conscientização sobre a importância da autonomia e da responsabilidade individual, por parte do aluno que estuda na modalidade a distância;

(6) conhecimento sobre os direitos e deveres dos agentes envolvidos, incluindo a divulgação ampla do Código Disciplinar Discente, com destaque reiterado várias vezes sobre os riscos do plágio. Esse é considerado uma falta grave e pode levar a reprovação e a expulsão do aluno da Universidade. Contudo, o acesso à internet parece ter contribuído para o crescimento dessa prática, por isso essa recomendação se faz pertinente;

(7) oferecimento de Biblioteca Virtual, com materiais digitalizados relacionados aos conteúdos do curso e,

(8) capacidade analítica e compreensiva dos coordenadores, professores e tutores no sentido de contextualizar as condições de vida do aluno-trabalhador que estuda a distância e permanece no mercado de trabalho. Considera-se que essa será uma discussão permanente em cursos de pós-graduação Lato Sensu, sendo este um desafio presente que implica na administração do tempo e na análise do perfil discente para amparar as decisões político-pedagógicas dos cursos.

Pode-se apontar como limitação deste estudo o fato dos questionários terem sido disponibilizados online, para preenchimento dos alunos, logo após a apresentação do trabalho de conclusão de curso para a banca de professores avaliadores, ocasião em que foi divulgada a situação final no curso (aprovado ou reprovado) e esta proximidade de tempo, pode ter interferido nos argumentos e nos desabafos apresentados, influenciando positiva ou negativamente os relatos. Assim, os autores deste estudo pretendem replicar a ampliar a pesquisa em outros cursos de graduação e especialização, envolvendo alunos, tutores e professores, com o objetivo de realizar análises comparativas que possam validar as informações aqui levantadas, com a intenção de estabelecer novas ferramentas de apoio e monitoramento para o processo de orientação do trabalho de conclusão de curso, em busca da otimização destas atividades.

\section{Referências Bibliográficas}

ALMEIDA, Maria Elizabeth. Tecnologia e Educação a Distância: Abordagens e Contribuições dos Ambientes Digitais e Interativos de Aprendizagem. ANPEd, 2003.

BELLONI, Maria L. Educação à distância. 3ed. Campinas: Autores Associados, 2003. FREIRE, Paulo. Educação como prática da liberdade. 28. ed. Rio de Janeiro: Paz e Terra, 1979.

FREIRE, Paulo. Pedagogia da autonomia: saberes necessários à prática educativa. 35 . Ed. São Paulo. Paz e Terra, 1996.

FREIRE, Paulo. Pedagogia da autonomia: saberes necessários à prática educativa. 16. ed. Rio de Janeiro: Paz e Terra, 2000.

LITTO, Fredic Michael; FORMIGA, Manuel Marcos Maciel (Orgs). Educação a distância: o estado da arte. São Paulo: Pearson Education do Brasil, 2009.

MAÇADA, L.Débora; TIJIBOY, Ana Vilma. Aprendizagem Cooperativa em Ambientes Telemáticos. IV Congresso RIBIE, Brasi1ia 1998. Disponível em http://sm.dei.uc.pt/ribie/docfiles/txt200342414721274.PDF Acesso em: 8 maio. 2010. MOORE, Michael G; ANDERSON, William G. Handbook of Distance Education. Lawrence Erlbaum Associates. New Jersey. Publishers Mahwah, 2003. 
NEVADO, Rosane Aragon. Ambientes virtuais de aprendizagem: do ensino na rede à aprendizagem $\quad$ em $\quad$ rede. $\quad$ Disponível em <http//www.tvebrasil.com.br/salto/boletins2005/nfa/tetxt2.htm>. Acesso: 8. maio 2010. SILVA, Marcos. Sala de Aula Interativa, 4. Ed. Rio de Janeiro: Quartet, 2006.

SCHLEMMER, Eliane. Metodologias para a educação a distância no contexto da formação de comunidades virtuais de aprendizagem. In: BARBOSA, Rommel Melgaço (Org.). Ambientes virtuais de aprendizagem. Porto Alegre: Artmed, 2005.

YIN, Robert K. Estudo de Caso: Planejamento e Métodos. 2. ed. Porto Alegre: Bookman, 2001. 